\title{
KEPATUHAN IBU HAMIL DALAM MEMINUM TABLET Fe DENGAN KEJADIAN ANEMIA DI PUSKESMAS MACCINI SAWAH KOTA MAKASSAR
}

\section{COMPLIANCE OF PREGNANT MOTHER IN CONSUMING Fe TABLET WITH ANEMIA EVENT IN MACCINI SAWAH HEALTH CENTER, MAKASSAR CITY}

\author{
Raimundus Chalik*, Hidayati \\ "Poltekkes Kemenkes Makassar
}

\begin{abstract}
In Indonesia the low state of health is characterized by high maternal mortality. According to WHO, $40 \%$ of maternal deaths in developing countries are associated with anemia in pregnancy. The most common cause of anemia in pregnancy is iron deficiency. The study aims to determine the relationship of adherence of pregnant women in taking Fe tablets with the incidence of anemia. The type of research is analytic descriptive with cross sectional approach. Data collection was carried out in June-August 2018 at the Puskesmas Maccini Sawah Kota Makassar. Data collection is carried out prospectively. The number of samples is 93 people selected by purposive sampling. The MMAS-8 instrument was used to assess medication adherence. Bivariate analysis using the chi square test and multivariate analysis with multiple logistic regression.

The results of the study found $84.9 \%$ of pregnant women were adherent to taking Fe tablets. From this result $67.1 \%$ not anemia and $32.9 \%$ anemia. Chi-square analysis found the variables associated with the incidence of anemia were compliance and parity $(p<0.05)$. Furthermore, in the multiple logistic regression analysis found only the adherence variable had a significant relationship with the incidence of anemia $(p<0.05, O R 5,096)$. The results of this study concluded that the risk of anemia was 5,096 times in pregnant women who were not adherent to taking Fe tablets compared to those who were adherent.
\end{abstract}

Keywords: adherence, anemia, pregnant women, Puskesmas Maccini Sawah.

\section{ABSTRAK}

Di negara Indonesia rendahnya kesehatan ditandai dengan masih tingginya angka kematian ibu. Menurut WHO, 40\% kematian ibu di negara berkembang berkaitan dengan anemia dalam kehamilan. Penyebab paling umum dari anemia pada kehamilan adalah kekurangan zat besi. Penelitian ini bertujuan untuk mengetahui hubungan kepatuhan ibu hamil dalam meminum tablet Fe dengan kejadian anemia. Jenis penelitian ini adalah deskriptik analitik dengan pendekatan cross sectional. Pengambilan data dilaksanakan pada bulan Juni-Agusstus 2018 di Puskesmas Maccini Sawah Kota Makassar. Pengambilan data dilakukan secara prospektif. Jumlah sampel sebanyak 93 orang yang dipilih secara purposive sampling. Instrumen MMAS-8 digunakan untuk mengukur kepatuhan pengobatan. Analisis bivariat menggunakan uji chi square dan analisis multivariat dengan regresi logistik ganda.

Hasil penelitian menemukan $84,9 \%$ ibu hamil yang patuh meminum tablet $\mathrm{Fe}$. Dari nilai ini $67,1 \%$ yang tidak mengalami anemia dan $32,9 \%$ anemia. Analisis chi-square menemukan variabel yang berhubungan dengan kejadian anemia adalah kepatuhan dan paritas $(p<0,05)$. Selanjutnya pada analisis regresi logistik ganda menemukan hanya variabel kepatuhan saja yang memiliki hubungan yang bermakna dengan kejadian anemia $(p<0,05, O R 5,096)$. Hasil penelitian ini menyimpulkan bahwa risiko anemia 5,096 kali pada ibu hamil yang tidak patuh dalam meminum tablet Fe dibadingan dengan yang patuh.

Kata kunci : kepatuhan, anemia, ibu hamil, Puskesmas Maccini Sawah

\section{PENDAHULUAN}

Suplementasi zat besi perlu sekali diberlakukan bahkan kepada wanita yang berstatus gizi baik, karena kebutuhan ibu hamil akan zat besi meningkat sebesar $200-300 \%$. Jumlah sebanyak ini tidak mungkin tercukupi hanya melalui diet (Arisman, 2009). Suplementasi tablet $\mathrm{Fe}$ adalah salah satu strategi untuk meningkatkan intake zat besi yang berhasil hanya jika individu mematuhi aturan konsumsinya (Departemen Gizi dan Kesehatan Masyarakat FKM-UI, 2012).

Ketidakpatuhan dalam minum tablet $\mathrm{Fe}$ dapat menyebabkan kekurangan kadar hemoglobin 
dalam darah atau anemia. Anemia yang tidak diatasi membahayakan ibu hamil dan janin yang dikandungnya. Menurut Manuaba (2010) pengaruh anemia dalam kehamilan dapat menyebabkan abortus, hambatan tumbuh kembang, mudah terjadi infeksi, ancaman dekompensasi kordis, ketuban pecah dini, persalinan anterparum. Selain membahayakan pada masa kehamilan, anemia juga bahaya pada saat persalinan dan kala nifas, sehingga penting pemenuhan zat bei pada ibu hamil untuk menghindari anemia.

Hasil penelitian Sadariah tahun 2012, di Puskesmas Bara-Baraya diperoleh bahwa dari 110

\section{BAHAN DAN METODE}

Jenis penelitian ini adalah deskriptik analitik dengan pendekatan cross sectional. Peneltian ini dilaksanakan pada bulan Januari-Oktober 2018. Pelaksanan pengambilan data dilakukan pada bulan Juni-Agustus 2018 di Puskesmas Maccini Sawah Kota Makassar. Populasi dalam penelitian ini adalah ibu hamil trimester III yang melakukan ANC dan mendapat tablet Fe di Puskesmas Maccini Sawah Kota Makassar selama periode Juni-Agustus 2018 yang berjumlah 122 orang. Sampel sebanyak 93 orang dengan kriteria inklusi ibu hamil trimester III dan telah mendapatkan tablet Fe pada kunjungan antenatal sebelumnya, bersedia ikut serta dalam penlitian dan mengisi inform consent. Kriteria eksklusi sampel dalam penelitian ini adalah ibu hamil dengan hiperemesis dan ibu hamil yang menderita penyakit infeksi kronis.

Teknik pengumpulan data menggunakan lembar observasi, dan kuesioner MMAS-8 untuk mengukur kepatuhan minum tablet Fe. Pengumpulan data secara prospektif. Dalam penelitian ini data HASIL PENELITIAN

Analisis Univariat sampel ibu hamil terdapat $43 \quad(39,9 \%)$ yang menderita anemia didapatkan $16(37,2 \%)$ ibu yang tidak patuh dalam minum tablet Fe.

Rendahnya kepatuhan ibu hamil dalam minum teblet $\mathrm{Fe}$ merupakan salah satu penyebab angka prevalensi anemia masih tetap tinggi (Purwaningsih, dkk.,2004). Dari penelitian yang dilakukan di Puskesmas di Yogyakarta, sekitar 40\%$50 \%$ ibu tidak patuh minum tablet Fe. Penelitian Wipayani (2008) di Semarang, dari 30 orang responden, $30 \%$ diantaranya tidak patuh minum tablet Fe (Maisa, 2010).

yang dikumpulkan adalah data primer dan data sekunder. Data primer meliputi karakteristik ibu hamil (usia, paritas, anemia) dan kepatuhan ibu hamil minum tablet $\mathrm{Fe}$, dan data dari hasil pemeriksaan $\mathrm{Hb}$. Untuk kejadian anemia digunakan hemometer digital. Data sekunder dalam penelitian ini meliputi data dari studi literatur, dari instansi puskesmas, data dari kartu kontrol pemeriksaan kehamilan. Variabel tergantung adalah anemia. Variabel bebas adalah kepatuhan, paritas, dan umur.

Analisis univariat dilakukan untuk melihat distribusi frekuensi dan persentase pada setiap variabel. Analisis bivariat mengunakan uji chi square untuk mengetahui hubungan antara kepatuhan minum tablet $\mathrm{Fe}$, paritas, dan umur terhadap kejadian anemia. Analisis multivariat menggunakan regresi logistik ganda untuk mengetahui bagaimana hubungan yang murni antara variabel bebas utama dengan variabel tergantungnya.

Tabel 1. Karakteristik ibu hamil yang berkunjung di Puskesmas Maccini Sawah periode Juni - Agustus $2018(n=93)$

\begin{tabular}{|c|c|c|}
\hline Karakteristik & Frekuensi (n) & Persentase (\%) \\
\hline \multicolumn{3}{|l|}{ Usia (tahun) } \\
\hline$<20$ & 13 & 14,0 \\
\hline $20-35$ & 67 & 72,0 \\
\hline$>35$ & 13 & 14,0 \\
\hline Jumlah & 93 & 100 \\
\hline \multicolumn{3}{|l|}{ Paritas } \\
\hline Nullipara & 18 & 19,4 \\
\hline Primipara & 30 & 32,3 \\
\hline Multipara & 45 & 48,4 \\
\hline
\end{tabular}


Jurnal Media Keperawatan: Politeknik Kesehatan Makassar

Vol. 10 No 012019

e-issn : 2622-0148, p-issn : 2087-0035

\begin{tabular}{lll}
\hline \hline \multicolumn{1}{c}{ Jumlah } & 93 & 100 \\
\hline Kepatuhan & & \\
Patuh & 79 & 84,9 \\
Tidak Patuh & 15 & 15,1 \\
\hline Jumlah & 93 & 100 \\
\hline Anemia & & \\
Ya & 36 & 38,7 \\
Tidak & 57 & 61,3 \\
\hline & 93 & 100 \\
\hline
\end{tabular}

Analisis Bivariat

Tabel 2. Analisis hubungan kelompok umur dan kejadian anemia di Puskesmas Maccini Sawah periode Juni Agustus $2018(n=93)$

\begin{tabular}{ccccc}
\hline \multirow{2}{*}{ Umur (Tahun) } & \multicolumn{2}{c}{ Anemia } & \multirow{2}{*}{ Jumlah $(\%)$} & \multirow{2}{*}{ p value } \\
\cline { 2 - 3 } & Ya & Tidak & & \\
\hline$<20$ & $6(46,2)$ & $7(53,8)$ & $13(100)$ & \\
$20-35$ & $26(38,8)$ & $41(61,2)$ & $67(100)$ & 0,723 \\
$>35$ & $4(30,8)$ & $9(69,2)$ & $13(100)$ & \\
\hline Jumlah & $36(38,7)$ & $57(61,3)$ & $93(100)$ & \\
\hline
\end{tabular}

Tabel 3. Analisis hubungan paritas dan kejadian anemia di Puskesmas Maccini Sawah periode Juni - Agustus 2018 $(n=93)$

\begin{tabular}{|c|c|c|c|c|}
\hline \multirow{2}{*}{ Paritas } & \multicolumn{2}{|c|}{ Anemia } & \multirow{2}{*}{ Jumlah (\%) } & \multirow{2}{*}{$p$ value } \\
\hline & $\mathrm{Ya}$ & Tidak & & \\
\hline Nullipara & $10(55,6)$ & $8(44,4)$ & $18(100)$ & \multirow{4}{*}{0,195} \\
\hline Primipara & $12(60,0)$ & $18(40,0)$ & $30(100)$ & \\
\hline Multipara & $14(31,1)$ & $31(68,9)$ & $45(100)$ & \\
\hline Jumlah & $36(38,7)$ & $57(61,3)$ & $93(100)$ & \\
\hline
\end{tabular}

Tabel 4. Analisis hubungan kepatuhan dan kejadian anemia di Puskesmas Maccini Sawah periode Juni - Agustus $2018(n=93)$

\begin{tabular}{|c|c|c|c|c|}
\hline \multirow{2}{*}{ Kepatuhan } & \multicolumn{2}{|c|}{ Anemia } & \multirow{2}{*}{ Jumlah (\%) } & \multirow{2}{*}{$p$ value } \\
\hline & $\mathrm{Ya}(\%)$ & Tidak (\%) & & \\
\hline Patuh & $26(32,9)$ & $53(67,1)$ & $79(84,9)$ & \\
\hline Tidak Patuh & $10(71,4)$ & $4(28,6)$ & $14(15,1)$ & 0,006 \\
\hline Jumlah & $36(38,7)$ & $57(61,3)$ & $93(100)$ & \\
\hline
\end{tabular}

Analisis Multivariat

Analisis multivariat menggunakan regresi logistik ganda antara variabel bebas (variabel utama dan perancu) yang memiliki nilai $p>0,25$. Sebagai variabel utama adalah kepatuhan.

Tabel 5. Hasil analisis pemodelan I hubungan kepatuhan, paritas terhadap kejadian anemia pada ibu hamil di Puskesmas Maccini Sawah periode Juni - Agustus $2018(n=93)$ 


\begin{tabular}{lcccrrrr}
\hline Variabel Bebas & B & Wald & Sig. & Exp(B) & \multicolumn{2}{c}{$95 \%$ C.l.for Exp(B) } \\
\cline { 6 - 8 } Kepatuhan & 1,715 & 6,913 & 0,009 & 5,555 & 1,547 & Upper \\
Paritas (1) & $-0,829$ & 1,722 & 0,189 & 0,437 & 0,127 & 19,942 \\
Paritas (2) & $-1,130$ & 3,615 & 0,057 & 0,323 & 0,101 & 1,005 \\
\hline
\end{tabular}

Pada tabel 5 di atas terlihat bahwa variabel bebas dengan nilai $p<0,05 a d a l a h$ kepatuhan (variabel utama). Artinya kepatuhan akan dimasukkan ke dalam tahap pemodelan selanjutnya.

Tabel 6. Model akhir analisis multivariat hubungan kepatuhan, paritas terhadap kejadian anemia pada ibu hamil di Puskesmas Maccini Sawah periode Juni - Agustus $2018(n=93)$

\begin{tabular}{ccccccc}
\hline \multirow{2}{*}{ Variabel Bebas } & \multirow{2}{*}{$\mathrm{B}$} & \multirow{2}{*}{ Wald } & \multirow{2}{*}{ Sig. } & \multirow{2}{*}{$\operatorname{Exp}(\mathrm{B})$} & \multicolumn{2}{c}{$95 \%$ C.l.for $\operatorname{Exp}(\mathrm{B})$} \\
\cline { 6 - 7 } & & & & & Lower & Upper \\
\hline Kepatuhan & 1,628 & 6,511 & 0,011 & 5,096 & 1,459 & 17,803 \\
\hline
\end{tabular}

PEMBAHASAN

Hasil penelitian menemukan $84,9 \%$ ibu hamil yang patuh meminum tablet Fe. Hasil penelitian ini sejalan dengan penelitian Seck Jackson (2008) di India yang juga menemukan tingkat kepatuhan ibu hamil dalam meminum tablet $\mathrm{Fe}$ sebesar $80,74 \%$ dan penelitian Wungkana, dkk. (2016) sebesar 75,8\%. Namun beberapa penelitian lainnya bertentangan dengan hasil penelitian ini yang menemukan tingkat kepatuhan ibu hamil dalam meminum tablet Fe lebih rendah. Misalnya penelitian yang dilakukan oleh Heny Sepduwiana (2017) yang melaporkan kepatuhan ibu hamil di Rambah Samo 1 sebesar 21,2 \%, penelitian Adilestari (2017) di Mantrijeron Yogyakarta sebesar $31,7 \%$, Purnamasari (2016) di Bongor Tengah 43,4\%, dan penelitian Ohaeri, et al. (2016) di Akinyele, Ibadan $42 \%$.

Dari hasil respon dan wawancara dengan responden sebagian besar alasan ketidakpatuahan disebabkan karena lupa minum obat, efek samping pada sistem pencernaan berupa rasa mual dan muntah, nyeri perut, baunya tidak enak dan takut bayinya besar pada saat lahir, dan faktor lupa sebagai alasan utama. Masalah ini seharusnya dapat diatasi dengan memberikan konseling yang lebih baik selama kunjungan prenatal. Selanjutnya membuat strategi yang memungkinkan ibu hamil untuk dapat selalu mengingat untuk minum obatnya (seperti dengan menempatkan tablet Fe nya di tempat yang dapat mereka lihat setiap hari) mungkin dapat membantu mengatsi masalah ini (Habib et al. 2009). Dari beberapa penelitian lainnya juga menemukan beberapa alasan ketidakpatuhan ibu hamil dalam meminum tablet $\mathrm{Fe}$ adalah efek samping seperti mual, muntah, konstipasi, lupa, puasa, bayi lahir besar, dan tidak mendapat penjelasan yang baik dari petugas kesehatan tentang manfaat $\mathrm{Fe}$ selama masa kehamilan (Sajith et al. 2015 ; Ohaeri et al. (2016). Penelitian lainnya yang sejalan dengan penelitian ini yaitu penelitian Siabani et al. (2017), Karimi et al. (2014), Rezaei et al. (2010), dan Melamed, et al. (2007), yang juga menemukan faktor lupa sebagai alasan utama ketidakpatuhan ibu hamil dalam meminum tablet $\mathrm{Fe}$. Sementara Kiwanuka et al. (2017), Gereklioglu et al. (2016), Ugwu et al. (2014), dan Ogundipe et al. (2012), melaporkan bahwa alasan utama ketidakpatuhan ibu hamil dalam meminum tablet $\mathrm{Fe}$ adalah efek samping. Kejadian anemia pada penelitian ini ditemukan sebesar 38,7\% (36 orang). Angka tersebut mendekati data WHO $(35,2 \%)$ prevalensi anemia pada ibu hami di dunia tahun 2011. Hasil ini juga sejalan dengan penelitian Septadara (2017) yang menemukan kejadian anemia pada ibu hamil sebesar $39,5 \%$. Namun bertentangan dengan penelitian Adilestari (2017) sebesar 60,3\%, dan Damayanti (2017) sebesar 64,8\%. Bagaimanapun juga jumlah kejadian anemia pada penelitian ini tetap perlu mendapat perhatian penanganan karena dapat berdampak buruk bagi ibu yang sedang hamil dan saat akan melahirkan (dapat terjadi perdarahan) bahkan sampai kematian dan juga dapat berdampak negatif terhadap bayinya seperti lahir prematur, berat badan lahir rendah (BBLR), lahir dengan anemia, dan gangguan pada 
perkembangan kognitif (Abu-Ouf, Jan, 2015; Manauba, 2010). Hasil penelitian ini sejalan dengan penelitian Heny Sepduwiana (2017) yang juga menemukan kejadian anemia pada ibu hamil sebesar $42,4 \%$ (28 orang).

Dari hasil uji chi square menunjukkan hubungan kepatuhan dan anemia memiliki nilai $p<$ 0,05 . Selanjutnya uji chi square hubungan paritas dan anemia juga memiliki nilai $p<0,05$. Hasil uji $c h i$ square hubungan umur dan anemia memiliki nilai $p>$ 0,05 . Dengan perkataan lain umur tidak memiliki pengaruh yang signifikan terhadap kejadian anemia pada ibu hamil. Peneltian lainnya juga menemukan tidak terdapat hubungan anatar umur dan kejadian anemia pada ibu hamil (Damayanti, 2017 ; Mislih, 2014 ; Windarti, 2011). Namun hasil ini bertentangan dengn penelitian yang dilakukan oleh Permatatiwi (2017), Pane (2015), yang menemukan ada hubungan yang signifikan antara umur ibu hamil dan kejadian anemia.

Karena variabel kepatuhan dan paritas memiliki nilai $p<0,25$, dengan demikian kedua variabel tersebut akan dimasukkan pada tahap I pemodelan analisis regresi logistik ganda dengan variabel kepatuhan sebagai variabel utama dan paritas sebagai variabel perancu. Dari hasil uji statistik dengan regresi logistik menunjukkan variabel kepatuhan menunjukkan nilai $p<0,05$. Dengan demikian, variabel kepatuhan memiliki hubungan secara bermakna dengan anemia dan dipertahankan pada uji regresi logistik tahap pemodelan selanjutnya. Pada variabel paritas memiliki nilai $p>$ 0,05 . Dengan demikian, variabel paritas tidak memiliki hubungan secara bermakna dengan anemia dan dikeluarkan pada uji regresi logistik tahap selanjutnya. Pada tabel 8 menunjukkan hasil uji regresi logistik tahap pemodelan berikutnya antara variabel utama (kepatuhan) terhadap kejadian anemia. Dari hasil uji menunjukkan nilai $p<0,05$. Dengan demikian, variabel kepatuhan memiliki hubungan secara bermakna dengan kejadian anemia. Dari hasil ini dapat ditetapkan model baku emas adalah kepatuhan saja dan akan menjadi model akhir (tabel 8 dan 9). Dari hasil uji didapatkan nilai OR kepatuhan terhadap anemia adalah 5,096 $(95 \% \mathrm{Cl} 1,459-17,803)$. Nilai OR ini menyatakan bahwa resiko terjadinya anemia 5,096 kali lebih besar pada responden yang tidak patuh dibanding yang patuh. Hasil penelitian Damayanti (2017) juga menemukan hubungan yang bermakna antara kepatuhan hamil dalam meminum tablet Fe dengan kejadian anemia dengan nilai OR 8,107. Beberapa penelitian lainnya yang juga mendukung hasil penelitian ini yaitu Anggraini (2018), Adilestari (2017), Gebre (2015), Mandariska, 2014, Hidayah (2012), Hidayat dan Anasari (2012) yang menemukan bahwa ibu yang patuh mengkonsumsi tablet $\mathrm{Fe}$ tidak mengalami anemia.

Mengingat pentingnya $\mathrm{Fe}$ selama masa kehamilan dalam mencegah anemia defisiensi besi dan dampak buruk yang ditimbulkannya jika terjadi anemia selama masa kehamilan, maka dari hasil ini perlunya peningkatan edukasi, motivasi, dan monitoring kepada ibu hamil dalam meminum tablet Fe selama masa kehamilan. Strategi monitoring kepatuhan dapat dipilih dari beberapa metode yang ada sesuai dengan karakteristik responden, ketersediaan, dan mudah dilakukan. Edukasi dan konseling sangat perlu diberikan kepada ibu hamil saat kunjungan antenatal mereka ke puskesmas terkait manfaat utama dari tablet $\mathrm{Fe}$, baik bagi ibu maupun janinnya. Tablet $\mathrm{Fe}$ bukanlah obat yang diindikasikan untuk mengobati penyakit, tetapi sebagai suplemen yang dibutuhkan oleh ibu hamil untuk memenuhi kebutuhan akan zat besi selama masa kehamilan, Efek samping yang mungkin terjadi dan upaya pengatasannya. Efek samping samping tidak berbahaya dan bersifat ringan. Oleh karena itu tablet Fe harus diminum secara teapt dan teratur, tidak perlu khawatir atau takut akan dampaknya. Cara minum, sebaiknya diminum dengan air puth, jangan dimimum bersama susu, kopi atau teh, dan sebaiknya diminum di malam hari. Disamping itu informasi penyimpanan tablet $\mathrm{Fe}$ juga perlu disampaiakan dengan baik, karena tablet $\mathrm{Fe}$ dapat mengalami oksidasi jika disimpan di tempat yang terbuka, terkena udara lembab, jika hal ini terjadi maka tablet Fe menjadi tidak efektif lagi.

\section{UCAPAN TERIMA KASIH}

Penelitian ini tidak akan mungkin terjadi tanpa dukungan banyak orang. Saya berterima kasih kepada Kepala Puskesmas Maccini Sawah karena telah mengizinkan saya untuk melakukan penelitian, Agustian Ipa, Direktur Poltekkes kemenkes Makassar, Ismail Ibrahim, Ketua Jurusan Farmasi atas dukungannya pada pelaksanaan penelitian ini. Saya ingin menyampaikan cinta dan terima kasih kepada keluarga saya atas pengertian dan dukungan mereka selama penelitian ini. Tanpa dukungan mereka semua penelitian ini tidak dapat diselesaikan 


\section{DAFTAR PUSTAKA}

Abu-Ouf NM, Jan MM. 2015. The impact of maternal iron defciency and iron defciency anemia on child's health. Saudi Med J. 2015;36(2):146-9

Adilestari, W. 2017. Hubungan Kepatuhan Ibu Hamil Mengkonsumsi Tablet Fe Dengan Kejadian Anemia Di Puskesmas Mantrijeron Yogyakarta

Anggraini PD. 2018. Faktor - Faktor yang Berhubungan Dengan Kejadian Anemia Pada Ibu Hamil di Wilayah Kerja Puskesmas Tanjung Pinang Tahun 2018. Jurnal Kebidanan Vol.7 No.15 April 2018 Issn.2089-7669

Arisman. 2009. Prinsip Dasar IImu Gizi. Jakarta: Gramedia Pustaka Utama

Damayanti D. 2017. Hubungan Faktor Internal dan Eksternal Dengan Kejadian Anemia Pada Ibu Hamil Trimester III di Wilayah Kerja PuskesmasTeladan Kecamatan Medan Kota

Departemen Gizi dan Kesehatan Masyarakat FKM UI. 2012. Gizi dan Kesehatan Masyarakat. Jakarta: Rajawali Pers.

Gebre, A. 2015. Assessment of Factors Associated with Adherence to Iron-Folic Acid Supplementation Among Urban and Rural Pregnant Women in North Western Zone of Tigray, Ethiopia: Comparative Study, International Journal of Nutrition and Food Sciences. 4 (2)

Gereklioglu C, Asma S, Korur A, Erdogan F, Kut A. Medication adherence to oral iron therapy in patients with iron defciency anemia. Pak J Med Sci. 2016;32(3):604-607. doi: http://dx.doi.org/10.12669/pims.323.9799

Habib F, Habib Zein Alabdin E, Alenazy M, Nooh R. 2009. Compliance to iron supplementation during pregnancy. J Obstetr Gynaecol 2009; 29:487-92

Hidayah, Wiwit dan Anasari, Tri. 2012. Hubungan Kepatuhan Ibu Hamil Mengkonsumsi Tablet Fe Dengan Kejadian Anemia Di Desa Pageraji Kecamatan Cilongok Kabupaten Banyumas Akademia Kebidanan YLPP Purwokerto. http://ojs.akbidylpp.ac.id/index.php/Prada/article/view/59

Hidayat A. 2011. Metode Penelitian Kebidanan dan Teknik Analisis Data. Jakarta : Salemba Medika http://drshafa.wordpress.com/2010/11/16/anemia-pada-bumil

Kiwanuka TS, Onnge S. Kiondo P, Namusuke F. 2017. Adherence to iron supplements among women receiving antenatal care at Mulago National Referral Hospital, Uganda-cross-sectional study. BMC Res Notes (2017) 10:510 DOI 10.1186/s13104-017-2834-z

Maisa, Esthika. 2012. Hubungan Antara Dukungan Keluarga Dengan Kepatuhan Konsumsi Tablet Fe Pada Ibu Hamil Di Wilayah Kerja Puskesmas Nanggalo Kecamatan Nanggalo Kota Padang. Skripsi. Universitas Andalas. http://repository.unand.ac.id/14036/. Diakses 13 Januari 2013.

Manauba. 2010. Ilmu Kebidanan, Penyakit Kandungan, Keluarga Berencana Untuk Pendidikan Bidan.

Mandariska. 2014. Hubungan Kepatuhan Mengkonsumsi Tablet Fe terhadap kejadian Anemia pada Ibu Hamil Trimester III di Puskesmas Kalijagar 1 Wonosobo

Mislih, Mahyuni. 2016. Faktor-Faktor yang Berhubungan dengan Kejadian Anemia pada Ibu Hamil di Wilayah Kerja Puskesmas Sukajaya Kota Sabang Tahun 2014. Skripsi. Universitas Sumatera Utara

Ogundipe O, Hoyo C, Østbye T, Oneko O, Manongi R, et al. 2012. Factors associated with prenatal folic acid and iron supplementation among 21,889 pregnant women in Northern Tanzania: A cross-sectional hospital-based study. BMC Public Health 2012; 12: 481

Ohaeri, Beatrice M.1, Joseph, Blessing E. 2016. Factors influencing adherence to routine iron supplementation among pregnant women in akinyele local government, ibadan. JMBR: A Peer-review Journal of Biomedical Sciences June 2016, Vol. 15 No. 1 pp 83-91

Pane, Fitri Yani. 2015. Faktor-Faktor yang Berhubungan dengan Anemia pada Ibu Hamil di Kelurahan Bandar Selamat Kecamatan Medan Tembung. Skripsi. Universitas Sumatera Utara.

Permatatiwi I, Yugho Y, Sutriyati. 2017. Faktor-Faktor Yang Berhubungan Dengan Kejadian Anemia Pada Ibu Hamil Di Puskesmas Pembina Palembang. Jurnal Ilmiah Umum Dan Kesehatan 'Aisyiyah Vol.2 No.1 Juni 2017

Purnamasari G. 2016. Hubungan Pengetahuan Dan Sikap Terhadap Kepatuhan Ibu Hamil Dalam Mengkonsumsi Tablet Fe Di Puskesmas Bogor Tengah. Maternity : Jurnal Kebidanan dan Ilmu Kesehatan Volume 3/Nomor 3/ November 2016 ISSN : $2407-2656$

Purwaningsih, Sri, dkk. 2004. Analisis Faktor-Faktor yang Mempengaruhi Ketidakpatuhan Ibu Hamil dalam Mengkonsumsi Tablet Besi. Diakses 21 April 2014. http://ejournal.undip.ac.id/index.php/jnc

Sadariah. 2012. Faktor Yang Berhubungan DenganKejadian Anemia Pada Ibu Hamil di Puskesmas Bara-Baraya Makassar Tahun 2012, Kebidanan UIT 
e-issn : 2622-0148, p-issn : 2087-0035

Sajith M et al. 2016. Correlations of adherence to iron supplements and prevalence of anemia in antenatal women. Int $J$ Reprod Contracept Obstet Gynecol. 2016 Oct;5(10):3448-3452 . www.jircog.org. pISSN 2320-1770 | elSSN 2320-1789. DOI: http://dx.doi.org/10.18203/2320-1770.jircog201 63421

Seck BC, Jackson RT.2007.Determinants of compliance with iron supplementation among pregnant women in Senegal. Public Health Nutr., 2008;11(6):596-605

Sepduwiana H, Sutrianingsih RNS. 2017. Hubungan Jarak Kehamilan dan Kepatuhan Mengkonsusi Tablet Fe dengan Kejadian Anemia pada Ibu Hamil di Wilayah Kerja Puskesmas Rambah Samo 1

Septadara, UL. 2017. Hubungan Kepatuhan Mengkonsumsi Tablet Fe Dengan Kejadian Anemia Pada Ibu Hamil Trimester III Di Puskesmas Mlati 1 Sleman Yogyakarta

Siabani S, Arya MM, Babakhani M, Rezaei F. 2017. Determinants of Adherence to Iron and Folate Supplementation among Pregnant Women in West Iran: A Population Based Cross-Sectional Study. Quality in Primary Care (2017) 25 (3): 157-163

Ugwu E, Olibe A, Obi S, Ugwu A. 2014 Determinants of compliance to iron supplementation among pregnant women in Enugu, Southeastern Nigeria. Nigerian J Clin Pract 2014; 17: 608-612

World Health Organization. 2012. Guideline: Daily Iron And Folic Acid Supplementation In Pregnant Women. Geneva:WHO Library Cataloguing-in-Publication Data.

Windarti. 2012. Gambaran Kejadian Anemia Ibu Hamil dan Faktor-Faktor yang Berhubungan di Wilayah Kerja Puskesmas Kismantoro Wonogiri Tahun 2012. Skripsi. Universitas Indonesia

Wipayani, M. 2008. Hubungan Pengetahuan Tentang Anemia dengan Kepatuhan Ibu Hamil Meminum Tablet Besi di Desa Langensari Kecamatan Ungaran kabupaten Semarang. http://skripsi-tesis.com. Diakses tanggal 4 April 2014

Wungkana EE, Punuh MI, Momongan NR. 2016. Hubungan Antara Frekuensi Antenatal Care Dan Ketaatan Konsumsi Tablet Fe Dengan Kejadian Anemia Pada Ibu Hamil Di Puskesmas Bahu Kota Manado 